\title{
Research Items
}

Anthropometry of the Maya Indians.-In accordance with the policy of the Carnegie Institution (Washington) for making Chichen Itzá, Yucatan, a focal point for correlated research in the archæology, anthropology, linguistics, and biology of Yucatan, Dr. Morris Steggerda, of the Department of Genetics of the Carnegie Institution, has undertaken a study of the physical and physiological characters of the Maya of the villages in the neighbourhood of Chichen Itzá (Publication No. 434, Carnegie Institution). 77 males and 56 females were examined, also 135 children; but the report on the children will appear later. The average age of the male subjects was 30.6 years, of the females $28 \cdot 8$. They claimed to be pure Maya, and although probably no genetically pure Maya exists in Yucatan, they may be regarded as relatively pure, with not more than one-eighth to three-sixteenths Spanish blood. The average eye colour is dark brown, and of the hair, black. The stature is $155 \cdot 2 \mathrm{~cm}$. for males and $142.8 \mathrm{~cm}$. for females, a range of $10-15 \mathrm{~cm}$. less than United States Indians. Their arms are long in relation to the stature, the lower arm in particular being longer in relation to the whole arm than in the white. They have broad shoulders, being as broad as Plains Indians, who are considerably taller. The Maya is very broad-headed, the cephalic index being 85, the females being 1-2 per cent more than the males. The face is broad, the nasal index still leptorrhine, the ears long and narrow. The relative chest girth in the Maya is astonishingly great, being 56 per cent of stature in males anid 58 per cent in females, as against 53 and 55 per cent for whites and 51 per cent for negroes of both sexes. The teeth are very good, 42 per cent of 88 adults having perfect teeth. The pulse rate of the Indian is low and the metabolism high, when compared with whites and negroes.

English Loan-words in Hindi.--According to a study of English loan-words in Hindi by Dhirendra Varma in Allahabad University Studies, vol. 8, pt. 1, an "English-educated middle-class gentleman" can scarcely speak a sentence in Hindi without using some English words ; and thus a Hindi jargon has grown up which is used invariably by the "English-educated" when speaking among themselves. Among uneducated Indians, English loan-words are in use with a vernacular pronunciation, which conforms to certain phonetic rules or principles. From the point of view of meaning, these words may be classified under certain main heads : (1) words used to convey ideas connected with foreign institutions, such as courts and offices, military and police, educational system, transport and communications, for example, kālij (college), injiniar (engineer), ōbarsiar (overseer); (2) articles introduced by foreign influence-dress, food and drink, machinery, objects of recreation, for example, burus (brush), baeslin (vaseline), timātar (tomato), pancar (puncture). In phonetics, an unfamiliar English sound is replaced by the nearest Hindi sound, while in some cases awkward sounds are dropped or new sounds are introduced to facilitate pronunciation, for example, engine becomes anjan, officer, āphsar ; diphthongs are converted into simple vowels, for example, paetmaen, pointsman ; a vowel appears to avoid conjunct consonants, phäram, farm, kilark, clerk ; or by prothesis, istēsan, station, iskūl, skull, astabal, stable. In consonantal changes, cerebral or dental sounds are substituted for English alveolars, for example, darjan, dozen, Sitambar, September ; $c$ and $j$ are substituted for $t, f$, and $d z$, for example, cāk, chalk; $f$ and th are changed to the nearest stops, that is, $p h$ and $t h$, for example, phutbāl. By metathesis, general becomes jarmael, and signal singal ; $l$ is substituted for $n$, for example, lambar for number, and lemonade becomes lamlēt or laemunat, and so forth. The loan-words are mostly nouns. Neuters are assigned to masculine or feminine in differently ; while for purposes of declension English loan-words are treated like Hindi nouns. A full list of loan-words is appended.

Carbohydrates in Relation to Disease.-The abundance of cheap sugar is not only an embarrassment to the sugar industry, but, according to Dr. J. H. P. Paton, also brings risks in connexion with disease (Edin. Med. J., 39, No. 9, p. 556). Dr. Paton estimates that the average consumption of sugar is now in the neighbourhood of $100 \mathrm{lb}$. a head per annum. Sugar, as we use it, is not a natural food, and is devoid of all accessory food substances. Excessive consumption of sugar tends to upset digestion, is a factor in the production of rickets and dental decay, and leads to retention of water in the body, with an increased tendency to catarrhal affections. It is probably responsible for the increasing frequency of acidosis in the modern child, and it throws additional work on the pancreas, which may result in degeneration of this organ and diabetes. Experimentally, an abundant supply of glucose promotes the development of cancer in mice, and carbohydrate excess may therefore be one of the factors causing the increased prevalence of cancer.

African Birds and Temperature.-Dr. F.M. Chapman has shown that the distribution of bird-life in South America can be associated with climatic zones related to temperature, and applying a similar analysis to the birds of Africa, W. Wedgwood Bowen has found a zoning comparable to that in South America (Proc. Acad. Nat. Sci. Philadelphia, 84, 259; 1932). Knowledge of the distribution of many species is too inadequate to permit a thorough analysis of the zonal relationships ; but, ignoring the alpine and temperate zones, a rough analysis shows that 599 species are limited to the tropical zone and $\mathbf{5 5 0}$ to the subtropical zone, while only 100 occur indifferently in both zones, although 254 more which are common to both zones show subspecific differences which appear to be related to tem. perature. That is to say, of 1500 species only 100 appear to exhibit no change attributable to temperature. Although the distribution of the vegetation belts in Africa is mainly determined by rainfall, yet the study of Shantz's vegetation map shows that, with one notable exception, each of the various vegetation types may be classified roughly according to life zones (apparently not a chance distribution), and even the exception, the "acacia-tall grass savanna", which ranges widely through tropical and subtropical zones, may, the author thinks, be divisible, from the point of view of bird distribution, into tropical and subtropical portions.

Butterflies of the District of Columbia.--Bulletin 157 (1931) of the United States National Museum is devoted to an extensive memoir (366 pp.) entitled "The Butterflies of the District of Columbia and Vicinity". Its author, Mr. Austin H. Clark, who is curator in the Museum, has in this work provided an admirable non-technical guide to the rich butterfly fauna of the area under consideration. Each species is discussed at variable length, according to any special features of interest associated with it. Also, each species has one or more illustrations devoted to 
it, and these figures are comprised in some sixty-four half-tone plates bound at the end of the letterpress. In the long introductory chapter the author contributes a number of interesting remarks and observations on butterfly behaviour. Of especial note is the section dealing with pressure of population, since, in many of the species, he finds that if the males increase beyond a certain proportion they seem incapable of living amicably together in the presence of the females. A familiar sight is a shrinking puddle tenanted by gay companies of newly emerged male butterflies. These, according to the author, are examples that have been driven from over-populated areas by being incessantly tormented by other males. Requiring water, these fugitives naturally resort to the moisture found in puddles, where, in the absence of the females, they exist peaceably. Many of the common roadside butterflies are also stated to be exiles and consist of newly emerged males. They appear to be unable to cope with the older males in their natural habitats and are driven to areas beyond where the females live. As they mature, and the older males die off, they are able to fly back to the fields and, in their turn, drive out any younger and less lusty rivals. Sections devoted to butterflies and storms, the extermination of one species by another, migration, and other features of the biology of these insects are also included in this paper.

Storage of Fruit by Freezing.-Dr. J. Barker and Mr. T. Morris have just published a very interesting leaflet on the comparative values of different methods of storing fruit by freezing (Dept. Sci. and Ind. Res. Food Investigation Leaflet No. 2, 9 pp., 1932). The principles and practice of preservation by cold storage are discussed. Freezing alone often results in an inferior product due to the activities of enzymes when thawing takes place. Refrigeration with sugar or syrup prevents the browning of such fruits as plums and cherries during storage, and the destruction of the enzymes of peas or beans by heating slightly before cold storage gives successful results. Quick freezing and freezing in a vacuum or under an inert gas have also been investigated. The special considerations relating to the cold storage of English plums are set forth by Dr. Franklyn Kidd and Dr. C. West in Leaflet No. 1 of the same series (6 pp., 1932). The effects of storage temperature, handling, fungal rotting, packing, type of store, and climatic conditions before harvesting are all discussed. The report, though short, gives the results of ten years' intensive work upon the problem.

Bacteriophage of Pseudomonas radicicola.-An interesting paper entitled "Studies on Bacteriophages of the Root Nodule Organisms ", by Dr. S. V. Desai, dealing with the effect of certain bacteriophages on the activity of the root nodule organisms of leguminous plants, has recently appeared (Indian J. Agr. Sci., vol.2, pt. 2., 1932). Several strains of bacteriophage were isolated, and it was found that media which were suitable for initial separation were not good for the increase of virulence of the bacteriophage. The different strains were not specific for the various strains of the bacterial host, and it is suggested that there is only one bacteriophage for Pseudomonas radicicola, no matter what its host plant may be. The lytic principle was inactivated by heating to $75^{\circ} \mathrm{C}$. for five minutes. The results suggest further experiments to determine what part the bacteriophage plays under field or garden conditions. It has been found difficult to separate the organism and its bacteriophage, and it seems possible that the presence or absence of the latter may bear an intimate relation with the observed behaviour of the former.
Correlation of Coal Seams by Plant Spores.-The correlation of coal seams has usually depended on consideration of the associated shales and, in particular, the fossil-bearing bands. One of the most characteristic features of coals are those plant remains which have escaped destruction in the process of coal formation. Of late years, the means for identifying and even isolating the spore exines which are resistant to decay have been perfected and thus provide a method of correlation which may offer advantages over the study of fossils in adjacent strata. This method has been applied to the Parkgate seam in the Yorkshire area, and the Fuel Research Division of the Department of Scientific and Industrial Research has now, in Paper 23 of the Physical and Chemical Survey of National Coal Resources entitled "The Significance of Spores in the Correlation of Coal Seams" (H.M. Stationery Office, 2s. net), reported the extension of the study to the Barnsley and Silkstone seams in the same area. In all, 30 types of spore have been distinguished, and although most of them are too few in number or too irregular in distribution to use in identification, there is evidence that certain types are characteristic of certain seams, and the force of these conclusions may grow with increase in the number of observations.

Swedish Rainfall.-The report of the Swedish rainfall stations for 1931 has been published by the Statens Meteorologisk Hydrografiska Anstalt in the Arsbok, No. 13, pt. 2. The data come from 698 stations spread throughout the State. Their distribution is shown on a large-scale map. For every month in the year there is a detailed record of every station and a map of the rainfall. The year proved to be exceptionally wet, with a rainfall that averaged 142 per cent of the normal over the whole country. Only two provinces had a year's total below the average, and many had more than twice the normal rainfall. On the whole, the northern parts were the driest and the areas of the central depression the wettest.

Existence of a Heavy Lead Isotope.-K. Murakawa has published recently a note on the hyperfine structure in the spectrum of lead (Scientific Paper No. 371, Tokyo) which illustrates both the value and difficulty of such work. In it he confirms the existence of the light lead isotope $\mathrm{Pb}^{204}$ found by Schuler and Jones in a similar manner, but also claims, in opposition to Kopfermann, that there is a satellite to $\lambda 4057$ which must be attributed to a heavy isotope $\mathrm{Pb}^{210}$. He finds similar satellites to $\lambda \mathbf{3 6 8 3}$ and $\lambda 4387$. A Lummer-Gehrcke interferometer patterm for 4387 is reproduced showing the supposed $\mathrm{Pb}^{210}$ component, although without the corresponding microphotometer record. The abundance ratio for $\mathrm{Pb}^{204}$ and $\mathrm{Pb}^{207}$ is given as $1: 25$, and the ratio for $\mathrm{Pb}^{204}$ and $\mathrm{Pb}^{210}$ as $8: 1$.

Thermionic Emission.-The subject of thermionics has developed in a few years from the method of studying the electrical properties of matter to being the basis of one of the world's widest commercial applications of physical science. Richardson was the first to state, thirty years ago, that electrons, normally retained in a substance by a potential discontinuity at its surface, are able, when the body is heated, to escape through the surface and so constitute an electric current. The literature of the subject is now widespread and much of it is very abstruse. It was decided by the Radio Research Board that a critical survey of the literature would be of real value to engineers and other scientific workers. The work was entrusted to Dr. W. S. Stiles, of the National Physical Laboratory, and is now published (Radio Research Report No. 11. London: H.M.S.O., 2s.6d.). The author 
gives a clear and comprehensive survey of all the main results obtained in researches in the various branches of the subject, together with a lengthy and carefully compiled bibliography, which includes references to all the important papers published up to December 1930. This book will prove of great value to everyone interested in thermionics. The author sometimes gives useful hints showing how formulæ given by different authors can be reconciled. His abstracts also will enable the investigator to see what original papers he should consult.

Highly Cracked Gasoline.-In the April number of Industrial and Engineering Chemistry, Messrs. C. R. Payne and Alexander Lowy give an interesting account of their work on the study of composition of cracked petrol before and after heat-treatment. Their method, briefly, was to subject this petrol to a temperature of about $300^{\circ} \mathrm{C}$., which is actually below the temperature employed in the cracking process, and they reached some interesting conclusions. It was found that the percentage of unsaturated hydrocarbons was decreased by the heat and pressure treatment in all the fractions isolated. The percentage of naphthenes in the whole distillate up to $201 \cdot 5^{\circ} \mathrm{C}$. was increased by the treatment. Additional changes are considered to be attributable to polymerisation, such as increase of material boiling above $201 \cdot 5^{\circ} \mathrm{C}$. by about 4 per cent; disappearance of probable presence of cyclo-alkenes; and formation of hydrocarbons containing hydrogen atoms easily replaceable by halogen. Regarding the composition of the cracked petrol, benzene and toluene were identified in selected fractions ; in one fraction, boiling from $20 \cdot 4^{\circ}$ to $35^{\circ} \mathrm{C}$., the presence of methylcyclobutane was inferred. A further interesting point is that, in general, the proportion of unsaturated hydrocarbons tends to decrease as the boiling point increases; while in a similar way, the proportion of paraffinic hydrocarbons decreases, and the percentage of naphthenes and aromatics increases, as the boiling point is raised. Although the paper is a comparatively short one, it contains some valuable data on the physical and chemical properties of the various fractions, not easily accessible elsewhere; in particular, the refractive indices on ordinary and treated fractions provide some interesting contrasts.

\section{Astronomical Topics}

The Total Solar Eclipse of Aug. 31.-Further bulletins from Science Service, Washington, indicate that several observing parties obtained a fair measure of success. The U.S. Naval Observatory party at Limerick, Maine, was able to carry out its full programme, though thin cirrus cloud was passing. The General Electric Company sent up an aeroplane at Concord, N.H., which reached perfectly clear sky; the moon's shadow was seen for three minutes before and after totality. The Harvard party at Portland, Maine, had a completely clear sky. The Greenwich party at Parent obtained a satisfactory photograph of the flash spectrum extending from $H_{a}$ to the $H$ and $K$ calcium lines; but the attempt to obtain the infrared portion failed.

At least three different parties of observers, seeing that conditions at their stations were almost hopeless, made dashes by motor cars to regions where the clouds were less dense, and were successful in obtaining views of the eclipse, though of course there was not time to transport large instruments. Excellent roads contributed to the success of this novel resource.

Astronomical Notes for October.-Venus is well placed for observation as a morning star in Leo; it has passed its greatest brilliance, but is still of magnitude $-3 \cdot 7$. The illuminated fraction of the dise increases from $0 \cdot 62$ to 0.73 , the diameter diminishes from $19^{\prime \prime}$ to $15^{\prime \prime}$. There is a conjunction of Venus and Jupiter (distance apart $7^{\prime}$ ) on the morning of Oct. 20 ; they will be high enough for convenient observation soon after 4 A.M. ; it will give an opportunity to compare their surface brightness, and hence their albedoes.

Mars is a morning star, moving from Cancer to Leo ; its diameter increases from $5^{\prime \prime}$ to $6^{\prime \prime}$; it will be nearly $14^{\prime \prime}$ at the nearest approach to the earth on March 3. Mars will remain fairly near Jupiter throughout this apparition ; their least distance apart will be $16^{\prime}$ on June 4. Mars will make a near approach to the moon's south limb at 6.40 A.M. on Oct. 24 next. There will be an occultation in Scotland.

Saturn is still observable in the early part of the night; it is stationary in the eastern part of Sagittarius. The ring has begun to close; its major axis is $38^{\prime \prime}$, its minor $14^{\prime \prime}$; it will be edgewise about the end of 1936 .
Uranus is well placed for observation, being in opposition on Oct. 14; it is in the eastern part of Pisces; its diameter is $3 \cdot 6^{\prime \prime}$; a map of the faint stars near it is given in the B.A.A. Handbook for 1932. Its magnitude is $\mathbf{5 . 9}$, so that it is visible to a good eye.

There are two occultations of fifth magnitude stars visible in London; one disappears on Oct. 11 at $6^{\text {h }}$ $58 \frac{1}{2} \mathrm{~m}$ P.M., $40^{\circ}$ from the north point; the other reappears on Oct. 20 at $2^{\mathrm{h}} 36 \frac{1}{2} \mathrm{~m}$ A.M., $230^{\circ}$ from the north point.

Comet Peltier-Whipple was visible to the naked eye at the end of August ; it is now fainter, but still observable with moderate telescopes; the following ephemeris (for 0 hours on the days named) is a continuation of one by Messrs. Anderson and Cherring ton (Harvard Card 239).

\begin{tabular}{|c|c|c|c|c|}
\hline \multirow{2}{*}{ Sept. 30} & \multicolumn{3}{|c|}{ R.A. } & N. Decl. \\
\hline & $13^{\mathrm{h}}$ & $47 \mathrm{~m}$ & $21^{8}$ & $56^{\circ} 40^{\prime}$ \\
\hline Oct. & 13 & 52 & 52 & $54 \quad 37$ \\
\hline & 13 & 57 & 36 & $52 \quad 49$ \\
\hline 1 & 14 & 1 & 39 & $51 \quad 15$ \\
\hline 1 & 14 & 5 & 18 & 4952 \\
\hline 2 & 14 & 8 & 36 & $48 \quad 40$ \\
\hline 2 & 14 & 11. & 40 & 47 \\
\hline 2 & 14 & 14 & 31 & 4641 \\
\hline Nov. & 14 & 17 & 12 & $45 \quad 55$ \\
\hline & 14 & 19 & 41 & $45 \quad \mathrm{I}$ \\
\hline
\end{tabular}

Ephemerides for several periodic comets now under observation are given in the B.A.A. Handbook for 1932. It is to be hoped that all who have the means will join in the search for Tempel's comet of the November meteors; if the estimated date of perihelion is near the truth, it would be in Cancer or Leo during October. Search should also be made for Brooks's comet; it is in Pisces, and should be nearly midway between the two ephemerides given in the Handbook.

The most conveniently observable minima of Algol occur on Oct. 11 about $10^{\mathrm{h}} 36^{\mathrm{m}}$ P.M., and on Oct. 14 about $7^{\mathrm{h}} 24^{\mathrm{m}}$ P.M.

Summer Time ends at $2^{\text {h }}$ A.M. on Oct. 2 ; after that date the times given here are those shown by ordinary clocks. It is well to note that astronomical records should never be made in Summer Time, but always in true Greenwich time. 